\title{
Risk Factors Among Breast Cancer Patients Being Treated in Tertiary Level Hospital of Nepal: A Case Control Study
}

\author{
Asmita Rana', Anup Ghimire', Ram B Sah'1, Prajjwal Pyakurel', Nirmal P Shah² \\ ${ }^{1}$ School of Public Health and Community Medicine, ${ }^{2}$ Department of General Surgery, BP Koirala Institute of \\ Health Sciences, Dharan
}

\section{Corresponding author:}

\section{Asmita Rana. MBBS}

School of Public Health and Community Medicine, BP Koirala Institute of Health Sciences, Dharan Email:asmitarana01@gmail.com

\begin{abstract}
Introduction

Breast cancer is the leading cause of cancer death among females worldwide. Its incidence is on the rise in Nepal. However, the risk factors have not been studied in context of Nepal. The aim of this study is to identify and quantify the association of various risk factors with breast cancer in Nepal.
\end{abstract}

\section{Methods}

Hospital-based age-matched case-control study was conducted among 50 cases and 150 controls visiting BP Koirala Memorial Cancer Hospital, Bharatpur, Nepal. Semi-structured questionnaire was used to collect information on demographic characters, socio-economic parameters, reproductive history, dietary and personal habits, family history, history of contraception and history of benign breast disease. Height, weight, hip circumference and waist circumference were measured.

\section{Results}

Majority of the cases (52\%) belonged to the age group of 46-55 years. The significant risk factors were ethnicity of Dalit/Madhesi (AOR $8.222,95 \% \mathrm{Cl} 2.377-28.441$, p-value 0.001 ), parity of 3 to 5 (AOR 5.614, $95 \% \mathrm{Cl} 1.140-27.639, \mathrm{p}$-value 0.03$)$ and previous history of benign breast disease (OR $13.614,95 \% \mathrm{Cl}$ 3.229-57.391, $p$-value 0.001). Hysterectomy was found to reduce the risk of breast cancer (OR $0.122,95 \%$ $\mathrm{Cl} 0.017-0.826, \mathrm{p}$-value 0.03 ). Knowledge of breast self-examination was significantly higher among cases than controls (AOR 36.29, 95\% Cl 5.788-227.555, p-value < 0.001). Knowledge of mammography was significantly lower among cases than control $(\mathrm{AOR}=0.133,95 \% \mathrm{Cl}=0.028-0.647$, $\mathrm{p}$-value $=0.01)$.

\section{Conclusion}

This study showed a number of factors to be associated with the increased risk of breast cancer. It was observed that the mean age at diagnosis is a decade earlier than in Western countries. Genetic component was not significant in context of Nepal. It is hoped that the findings of this study will facilitate further exploration and evidenced-based preventive measures for Nepalese women.

Keywords: Benign breast disease, breast cancer, risk factors 